\title{
Effect of Alternate Corrosion and Fatigue on Fatigue Crack Growth Characterization of 2024-T4 Aluminum Alloy
}

\author{
Tianyu Zhang $\mathbb{D}^{1}{ }^{1}$ Yuting He $\mathbb{D},{ }^{1}$ Changfan Li $\mathbb{D},{ }^{2}$ Teng Zhang $\mathbb{D}^{1},{ }^{1}$ and Sheng Zhang ${ }^{1}$ \\ ${ }^{1}$ Aeronautics Engineering College, Air Force Engineering University, Xi'an 710038, China \\ ${ }^{2}$ Army Aviation Research Institute, Beijing 101121, China \\ Correspondence should be addressed to Tianyu Zhang; zz664191970@163.com
}

Received 18 November 2019; Revised 24 January 2020; Accepted 6 February 2020; Published 12 March 2020

Academic Editor: Vasilios Spitas

Copyright ( 92020 Tianyu Zhang et al. This is an open access article distributed under the Creative Commons Attribution License, which permits unrestricted use, distribution, and reproduction in any medium, provided the original work is properly cited.

To investigate the effect of alternate corrosion and fatigue on fatigue crack growth characterization of 2024-T4 aluminum alloy, the pure fatigue test, "corrosion + fatigue" test (commonly known as pre-corrosion fatigue), and the "fatigue + corrosion + fatigue" alternating test of single-sided notched specimen of 2024-T4 aluminum alloy were carried out. The fatigue crack life of alternate corrosion and fatigue is longer than that of the pre-corrosion fatigue when the corrosion time is the same. And the more the times of alternating, the longer the crack growth life will be. This is mainly because the fatigue crack growth rate will change suddenly, which will have a certain hysteresis effect on the fatigue crack growth. The corrosion and fracture morphology characteristics of the alternate test were examined by scanning electron microscopy (SEM), and the composition of corrosion products was examined by the energy dispersion spectrum (EDS). The prediction model of fatigue crack growth rate considering the alternating hysteresis effect of corrosion and fatigue based on the Paris formula was established, and the parameters and precision of the model were calculated and verified. The results show that the model has certain engineering application value.

\section{Introduction}

2024-T4 aluminum alloy is extensively applied considering its properties of high strength ratio, low density, and brilliant heat performance [1-4]. When an aircraft aluminum alloy structure is subjected to fatigue load and corrosion environment, the main form of material damage is corrosion fatigue damage [5]. Under the action of corrosion and fatigue, the mechanical properties, fatigue life, and fatigue crack growth life of the materials decrease greatly. The fatigue properties of aircraft structural materials under the action of corrosion are affected by the experimental loading frequency, stress ratio, stress level, and environmental factors, which have attracted the attention of many researchers [6]. Many researchers had reported that environmental factors enhance the development of corrosion, making the corrosion fatigue interaction acutely pertinent to the structural integrity of airframes based in sea-coast or marine environments [7-13]. Many scholars have established corrosion fatigue life prediction models for a variety of materials [14-18].
Li et al. [19] examined the initiation and early expansion of microcracks at corrosion pits with the Scanning Electron Microscope (SEM). The results showed a number of crack origins around the pits and the early expansion of fatigue crack was $\mathrm{K}_{\mathrm{I}} / \mathrm{K}_{\mathrm{II}}$ mixed mode. Menan and Henaff [20] carried out corrosion fatigue tests on 2024 aluminum alloy in different corrosion environments. It was demonstrated that fatigue and corrosion had a synergistic effect on crack growth. The methods and related factors were discussed to calculate fatigue crack growth [21-24]. Huang et al. [25] conducted pre-corrosion fatigue tests on 7075-T6 aluminum alloy and analyzed correlated coefficients for corrosion cracks and cracks according to the Pearson method. The equivalent crack size model was developed for both single crack and multicrack initiations with different stress levels. Ishihara et al. [26] proposed a pit depth function of both stress and corrosion time. It was demonstrated that a threshold stress could divide the specimen life into crack initiation and crack propagation, and pit growth rule could help to predict the fatigue life. Huang et al. [27] performed a 
corrosion fatigue experiment to study the pitting behaviors under both proportional and nonproportional loadings. The results showed that, for the proportion case, the pitting condition was more serious. The research on the damage evolution mechanism of materials under the action of corrosion fatigue and the influence of test parameters on the corrosion fatigue properties of materials has not been carried out. Life models that take into account various environmental factors and stress levels have not been established.

Alternate corrosion and fatigue refer to the process of alternating corrosion tests and fatigue tests for aircraft structures or materials. The damage state of the aircraft inservice environment is simulated by the alternate corrosion fatigue test mode, that is, the alternate process of corrosion on ground and fatigue in air. During high-altitude flights, the damage caused by fatigue loading is predominant, and the effect of corrosion damage in the high-altitude environment is negligible for the thin air and low temperature. However, when the aircraft parks in the airport, there is no fatigue loading, and the structural damage caused by corrosion is pronounced. Therefore, the process in which the aircraft is subjected to the alternating action of corrosion and fatigue can be simulated as the mode of "Corrosion + Fatigue + Corrosion + Fatigue $+\ldots$.." Considering that the aircraft will soon reach the high-altitude environment of more than $3000 \mathrm{~m}$ after take-off, the alternate mode of "Ground Corrosion + Air Fatigue" is generally adopted. And that is the pre-corrosion fatigue model. However, if there are many low-altitude flight subjects at sea, the alternate action model of corrosion and fatigue should be considered. Menan and Henaff [28] discussed the influence of loading frequency and alternate mode on the corrosion fatigue crack growth. $\mathrm{Li}$ et al. [29] used 7B04 aluminum alloy to carry out an alternate test of corrosion and fatigue with the purpose of investigating the reliability of life. Vucko et al. [30] evaluated fatigue performance of joined assemblies in a corrosion environment with alternate corrosion fatigue mode. The fatigue characteristics of 2024 aluminum alloy under the alternate action of "Fatigue + Corrosion + Fatigue" were analyzed earlier by Du [31]. It is found that the fatigue life of specimens under the alternating action of corrosion and fatigue is longer than that under the action of pre-corrosion when the specimens experience the same corrosion time. Further study found that the main reason for the long life under the alternating action of corrosion and fatigue was that the corrosion of the microcrack tip during the alternating action of corrosion and fatigue reduced the damage on the surface of the specimens. At present, there is little research on the prediction model of aircraft aluminum alloy life under the alternating action of corrosion fatigue. The influence of fatigue loading times and corrosion time on the life of alternating corrosion fatigue should be further studied.

In the process of crack growth, the typical fatigue crack growth curve can be divided into three parts according to the crack formation stage, growth stage, and rapid fracture stage. The crack formation stage is a low-speed region, in which the crack growth rate decreases rapidly with the decrease of the amplitude of stress intensity factor. The steady growth stage of the crack is the medium speed region where the crack growth rate has a good logarithmic linear relationship with the amplitude of the stress intensity factor. The fracture stage of the crack is a high-speed region, where the fatigue crack growth rate is large and the crack life is short. References $[32,33]$ show that the dispersion of fatigue crack propagation is largely caused by the complex environment, stress ratio, and load history. The dispersion of the crack in the stable growth stage is obviously less than that in the formation stage and the rapid fracture stage. Kim and Shim [34] studied the thickness effect of dispersion of fatigue crack propagation. The results show that the dispersion of the crack growth rate increases with the decrease of specimen thickness. Gary Harlow and Wei [35] conducted a reliability analysis on the formation of microcracks in aluminum alloy and steel under the action of corrosion and fatigue and established the probability model of microcrack growth. Zhu et al. [36-39] modified the original Fokker-Planck formula by Markov stochastic process and established the statistics of the crack growth process. Tsurui and Ishikawa [40] also proposed a random fatigue crack growth model similar to Lin's and studied the reliability of the crack growth process. Bogdanoff and Kozin [41] used Markov chain theory to study the random process of crack initiation and crack propagation. $\mathrm{Wu}$ et al. [42-44] established a universal method to analyze the randomness of crack growth by using a distance approximation method. The effect of corrosion environmental factors on multiaxial fatigue properties was studied, and accelerated alternate corrosion multiaxial fatigue tests were carried out in [45]. In the study of corrosion fatigue alternation, the main research focuses on the fracture characteristics of materials, but there are few studies on the crack growth characteristics under the action of corrosion fatigue alternation.

The pure fatigue test, "corrosion + fatigue" test (commonly known as pre-corrosion fatigue) and the "fatigue + corrosion + fatigue" alternating test of a singlesided notched specimen of 2024-T4 aluminum alloy were carried out in this paper. The effects of different corrosion periods of time and different alternating times of corrosion and fatigue on the fatigue properties, crack propagation, and microstructure of aircraft aluminum alloy were analyzed. The corrosion and fracture morphology characteristics were examined by scanning electron microscopy (SEM), and the composition of corrosion products was examined by the energy dispersion spectrum (EDS). The prediction model of fatigue crack growth rate considering the alternating hysteresis effect of corrosion and fatigue based on the Paris formula was established, and the parameters and precision of the model were calculated and verified. The results show that the model has certain engineering application value.

\section{Experimental Methods}

2.1. Specimens. Because the actual service structure is mainly subjected to tension-tension load, I cracking will be formed in a dangerous position. Therefore, the single notched 
specimen is used, and the direction of fatigue loading is the direction of extrusion. The geometry, dimensions, and loading method of the specimens are shown in Figure 1.

The chemical composition of the 2024-T4 aluminum alloy is reported in Table 1. The aluminum cladding of the specimens had been mechanically removed. The chemical composition of the 2024-T4 aluminum alloy is reported in Table 1. L, T, and S indicate, respectively, the longitudinal, long transverse, and short transverse directions of the grain's microstructure, as shown in Figure 1. In order to make the corrosion effect more consistent with the real environment, the specimens were anodized in sulfuric acid and sealed with hot water. The final thickness of the anodic oxide film was $8 \mu \mathrm{m}$.

In order to study the fatigue crack growth characterization under alternate action of corrosion and fatigue, it is necessary to prefabricate the crack at the gap of the specimens. The prefabricated cracks of the specimens were formed by linear cutting and fatigue loading. The tip of the prefabricated crack was perpendicular to the extrusion direction of the aluminum plate, and it was a straight penetration crack. The surface of the sample was polished with 1200\# metallographic sandpaper, which was easy to observe the length of crack growth with the crack measuring device. The length of the prefabricated crack was $1.5 \mathrm{~mm}$, the load used for the prefabricated crack was equal amplitude sinusoidal tension-tension load of $50 \mathrm{Mpa}$, and the stress ratio was 0.06 .

2.2. Alternate Experiment. Tension and tension fatigue tests were conducted under a sine load waveform at constant cyclic stress frequency $(f=20 \mathrm{~Hz})$ on the MTS 810 servo hydraulic test machine (MTS Systems Co., USA). The stress amplitude applied in the fatigue test was $50 \mathrm{MPa}$ and stress ratio $\mathrm{R}$ was 0.06 . According to ISO $16151: 2005$ standard, the accelerated cyclic tests with exposure to acidified salt spray, "dry" and "wet" conditions corrosion, were conducted. Each cyclic test lasted 8 hours, and the experimental temperature and humidity settings are shown in Figure 2. The solution used for the corrosion investigations was made of $5 \% \mathrm{NaCl}$ $(\mathrm{pH}=3.5 \pm 0.1)$ using distilled water and the deposited salt spray was $2 \mathrm{ml} /\left(\mathrm{h} \cdot 80 \mathrm{~cm}^{2}\right)$. The components and concentrations of the corrosion media of the accelerated corrosion solution are shown in Table 2.

The alternate corrosion and fatigue specimens were divided into three groups. The specimens for the pure fatigue test were the first group. The specimens for the precorrosion fatigue test were the second group, and the precorrosion test was carried out for $128 \mathrm{~h}$ and $192 \mathrm{~h}$, respectively, before fatigue test. The specimens for the alternate corrosion and fatigue test were the third group. The total corrosion time and the plan of the experiment are shown in Table 3. For example, a $48 \mathrm{~h}$ spray corrosion test was carried out when the crack grows to $5 \mathrm{~mm}, 7 \mathrm{~mm}$, and $9 \mathrm{~mm}$ in group 3-3.

The thickness of the specimen is $2 \mathrm{~mm}$, and the fatigue cracks are almost penetration cracks. Therefore, the surface crack length along the thickness of the specimen can be read

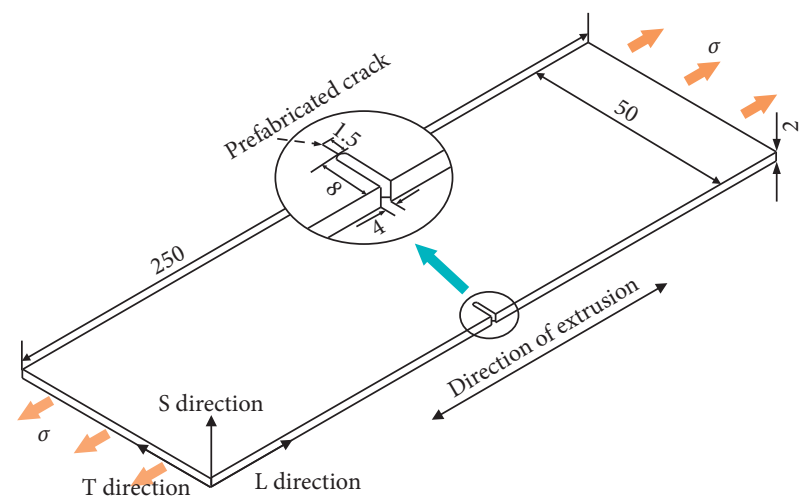

Figure 1: Geometry, dimensions, and loading method of specimens.

TABle 1: Chemical composition (wt. \%) of the 2024-T4 aluminum alloy.

\begin{tabular}{lccccccccc}
\hline Element & $\mathrm{Si}$ & $\mathrm{Fe}$ & $\mathrm{Cu}$ & $\mathrm{Mn}$ & $\mathrm{Mg}$ & $\mathrm{Zn}$ & $\mathrm{Ni}$ & $\mathrm{Ti}$ & $\mathrm{Al}$ \\
\hline $\begin{array}{l}\text { Weight } \\
\text { fraction (\%) }\end{array}$ & 0.10 & 0.22 & 4.62 & 0.54 & 1.60 & 0.22 & 0.09 & 0.13 & $\mathrm{Bal}$ \\
\hline
\end{tabular}

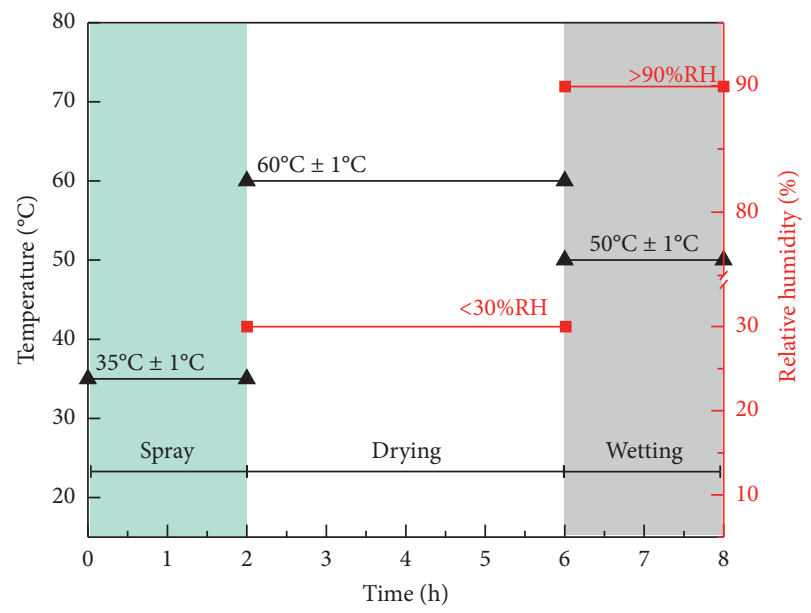

FIgURE 2: Temperature of the corrosion solution and drying environment, and humidity of the drying environment during cyclic immersion.

TABLE 2: The components and concentrations of the corrosion media of the accelerated corrosion solution.

\begin{tabular}{lc}
\hline Corrosive medium & Concentration \\
\hline $\mathrm{H}_{2} \mathrm{SO}_{4}(\mathrm{~mol} / \mathrm{L})$ & $4.06 E-03$ \\
$\mathrm{HNO}_{3}(\mathrm{~mol} / \mathrm{L})$ & $9.19 E-02$ \\
$\mathrm{NaCl}(\mathrm{g} / \mathrm{g})$ & $5 \%$ \\
Distilled water & - \\
\hline
\end{tabular}

as the crack growth length of the specimen during the fatigue crack growth test. The length of the prefabricated crack is taken as the initial position before the crack growth. When the crack extends $1.5 \mathrm{~mm}$ forward from the initial position, the number of cycles is calculated as zero. 
TABLE 3: The corroded time and alternate times of the test.

\begin{tabular}{lccc}
\hline $\begin{array}{l}\text { Alternate } \\
\text { corrosion } \\
\text { and fatigue }\end{array}$ & $\begin{array}{c}\text { Corrosion time of } \\
\text { each alternation }(\mathrm{h})\end{array}$ & $\begin{array}{c}\text { Crack } \\
\text { length }(\mathrm{mm})\end{array}$ & Alternate times \\
\hline $3-1$ & 96 & 5 & 2 \\
$3-2$ & 64 & 5,9 & 3 \\
$3-3$ & 48 & $5,7,9$ & 4 \\
$3-4$ & 64 & 5 & 2 \\
$3-5$ & 42.6 & 5,9 & 3 \\
$3-6$ & 32 & $5,7,9$ & 4 \\
\hline
\end{tabular}

\section{Results and Discussions}

3.1. Surface Appearance and Characterization. The slices of fatigue fracture after alternate action between corrosion and fatigue test were ground with a 1200 grit $\mathrm{SiC}$ paper. And the corrosion and fracture morphology characteristics were examined by scanning electron microscopy (SEM) and the composition of corrosion products was examined by energy dispersion spectrum (EDS) as shown in Figure 3. After alternating corrosion fatigue, the crack growth region of the specimen fracture was divided into three parts as shown in Figure 3(a): the first part is the corrosion area of the crack tip formed by the exposed part of the crack tip after corrosion test; the second part is the corrosion area of slip band, which is generated by the corrosion of the slip band at the crack tip along the crack growth direction during the corrosion process; The first part and the second part can be collectively referred to as the crack tip corrosion area. The third part is the fatigue growth region of the crack.

The corrosion region at the crack tip shows different surface characteristics from the fatigue growth region as shown in Figure 3(c). Due to the effect of corrosion, the crack section is dark and there are a lot of corrosion products on the surface in the corrosion area at the crack tip. From Figure 3(e), it can be seen that the pitting is very dense at the crack tip. And the corrosion products on the surface cracked, forming lumps with filamentous corrosion products being covered. Figure 3(f) shows that the filamentous corrosion products were composed of amorphous particles connected to each other and that the structure was loose, allowing easier absorption of water from the atmosphere. The mass percentage ratio of $\mathrm{Al}$ to $\mathrm{O}$ in area (2) of Figure 3(f), resulting from the EDS analysis, was used to determine that the filamentous corrosion products and the amorphous particles were also $\mathrm{Al}(\mathrm{OH})_{3}$. And it also can be seen that, with the accumulation of corrosion products, the crack tip also produces secondary cracks.

The corrosion region of the slip band of crack growth fracture was observed after the alternating action of corrosion and fatigue, as shown in Figure 3(b). The presence of $\mathrm{Si}$ and $\mathrm{Ca}$ in the EDS analysis of area (1) indicated that spray corrosion sediments contained those two elements. And the obvious characteristics of the slip band can be seen as shown in Figure 3(b).

The growth region of crack would produce dimples after the alternating test of corrosion and fatigue as shown in Figure 3(d). Due to the existence of two-phase particles and high potential at the dimple, corrosion occurs first and a large number of corrosion products are produced. As for the fatigue crack growth region, the crack growth morphology is the same as that under the pure fatigue action because it is only affected by the fatigue load.

The strength and fatigue resistance of materials are reduced after corrosion as proved by relevant investigations. Since the initial cracks of the specimens used in the test were obtained through fatigue loading, plastic region and a large number of slip bands will be formed at the tip of the crack after the initial crack preparation is completed. When there were cracks under the action of the corrosion environment, the slip bands and plastic regions at the crack tip become anode under the corrosion environment and corroded first due to their high potential. It is different from the action of pure fatigue. Under the action of corrosion, the plastic region and slip bands of the material dissolve continuously, and a large number of corrosion products are formed at the crack tip. With the accumulation of corrosion products, a local block cell will be formed at the crack tip, and the corrosion region of the slip band of the crack tip will be formed as shown in Figure 3(b). Compared with the crack growth region of pure fatigue, the number of slip bands generated after the alternation of corrosion fatigue will gradually disappear and decrease sharply, and a large number of corrosion products will be formed in the original slip region.

3.2. Crack Propagation Life. The average fatigue crack growth life of specimens in pure fatigue, pre-corrosion, and different alternating times of corrosion and fatigue was compared and analyzed, as shown in Figure 4. The alternating times of pre-corrosion tests are regarded as 1 .

As can be seen from Figure 4, the average fatigue crack growth life of specimens decreases with the increase of corrosion time. At 128 hours of pre-corrosion test and 192 hours of the pre-corrosion test, the fatigue crack growth life of specimens decreases by $34.3 \%$ and $24.6 \%$, respectively. In the alternate test of corrosion and fatigue, the average growth life of fatigue crack increases with the increase of the number of alternate times. When the total corrosion time is 128 hours and the number of alternate times is 2 times, the average fatigue crack growth life of the specimens is reduced by $22.5 \%$ compared with 128 hours of the pre-corrosion test. When the total corrosion time is 192 hours and the number of alternate times is 2 times, the average fatigue crack growth life of the specimens is reduced by $11.4 \%$ compared with 192 hours of the precorrosion test. In other words, when the alternating times of corrosion and fatigue are 2 times, the average fatigue crack growth life of the alternate specimen is reduced compared with the average crack growth life of the precorrosion specimen with the same corrosion time. When the alternating times of corrosion fatigue are 3 , the average fatigue crack growth life of the alternate corrosion and fatigue specimens corrosion is basically equal to the average crack growth life of the pre-corrosion specimen. When the alternating times of corrosion fatigue are 4 and the total corrosion time is 128 hours, the average fatigue 

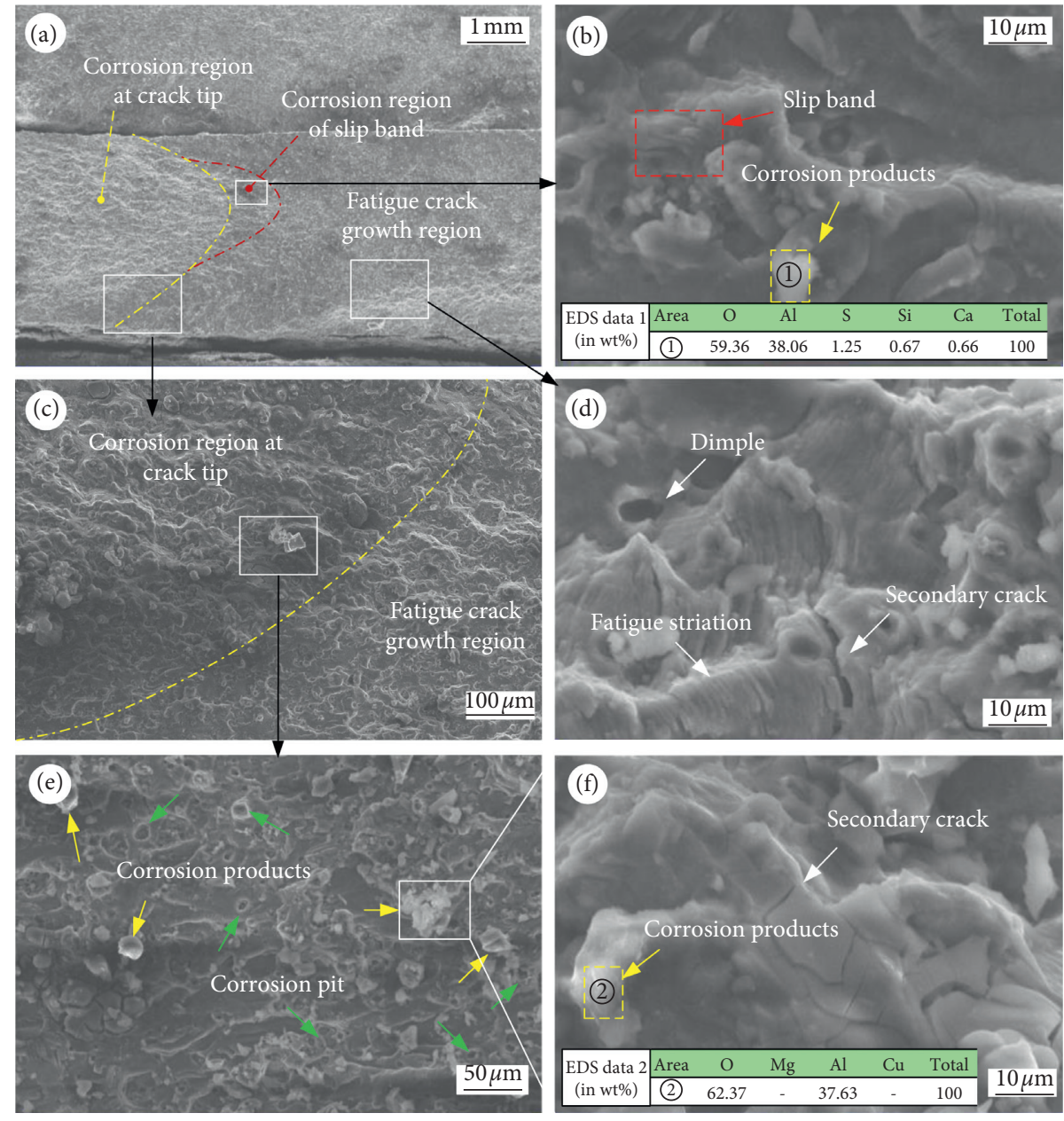

FIGURE 3: EDS data of corrosion products and microscopic morphology of specimen fracture: (a) microscopic morphology of specimen fracture; (b) local enlarged morphology of slip band and the EDS data of area (1); (c) local enlarged morphology of corrosion region at crack tip and fatigue crack growth region; (d) local enlarged morphology of fatigue crack growth region; (e) local enlarged morphology of (c); (f) local enlarged morphology of (e) and the EDS data of area (2).

crack growth life of the specimens is increased by $27.82 \%$ compared with the average fatigue crack growth life of the pre-corrosion test. When the alternating times of corrosion fatigue are 4 and the total corrosion time is 192 hours, the average fatigue crack growth life of the specimens is increased largely by $48.18 \%$ compared with the average fatigue crack growth life of the pre-corrosion test. The corrosion time of group 3-3 is 192 hours, which is longer than the specimens with 128 hours of pre-corrosion, but the average crack growth life is longer. Therefore, in the alternating test of corrosion and fatigue, the fatigue crack growth life of the specimen is not only affected by the total corrosion time but also affected by the alternating times of corrosion and fatigue. And with the increase of the alternating times of corrosion and fatigue, the fatigue crack propagation life increases significantly.

3.3. Crack Propagation Rate. According to the crack growth data recorded by the test results, the seven-point increasing polynomial method and linear interpolation method are used to calculate the crack growth rate under different crack lengths, and the results are shown in Figures 5-13.

As can be seen from Figures 5-7, the fatigue crack growth rate of the pre-corrosion fatigue test is similar to that of the pure fatigue test. The fatigue crack growth rate increases with the increase of the fatigue crack length, and the fatigue crack growth rate of the pre-corrosion fatigue test is higher than that of the pure fatigue test at the same crack length. The crack growth rate of pre-corrosion fatigue test is $10^{-4}$ magnitude, while that of pure fatigue test is $10^{-6}$ magnitude. Corrosion action will greatly increase the rate of crack growth. It can be clearly seen from Figures 8-13 that the fatigue crack growth rate is not continuous during the test of alternate corrosion and fatigue. The fatigue crack length during the test of alternate corrosion and fatigue will suddenly decrease, and the fatigue crack growth rate will increase rapidly in the subsequent fatigue process.

The test of alternate corrosion and fatigue has a hysteresis effect on the fatigue life of aluminum alloy. Similarly, the test alternate corrosion and fatigue has a hysteresis effect on the fatigue crack growth rate. The characteristics of crack 


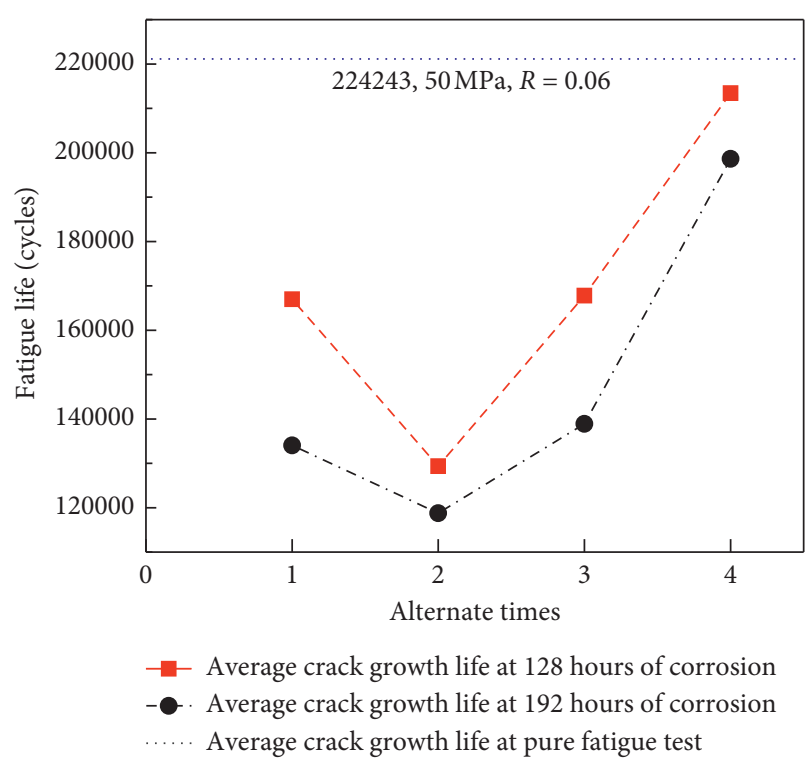

Figure 4: Average crack growth life at different hours of corrosion.

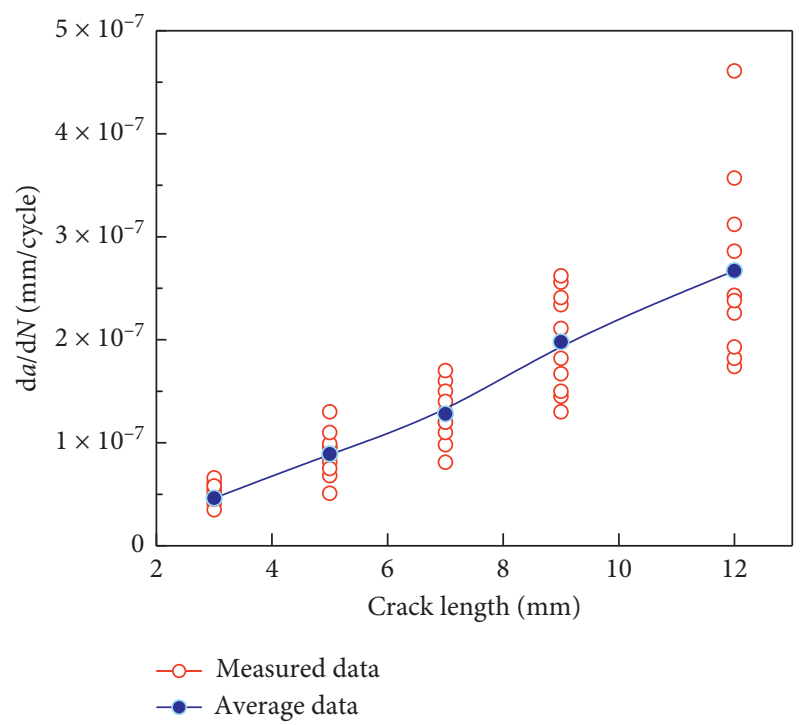

FIGURE 5: Crack growth rate at a given crack length in the pure fatigue test.

growth rate of the alternating action of corrosion and fatigue are closely related to the microscopic characteristics of fatigue crack growth.

Because the corrosion conditions of the corrosion test were conducted in the salt spray chamber, the factors of the corrosion test environment were constant. Therefore, corrosion action will further develop towards the direction of fatigue crack growth with the increase of corrosion time. The original plastic region and slip bands at the crack tip will further dissolve and the plastic region at the crack tip will lose its hysteresis effect on the fatigue crack growth. Therefore, the energy required for fatigue crack growth is greatly reduced, leading to a significant increase in fatigue crack growth rate.

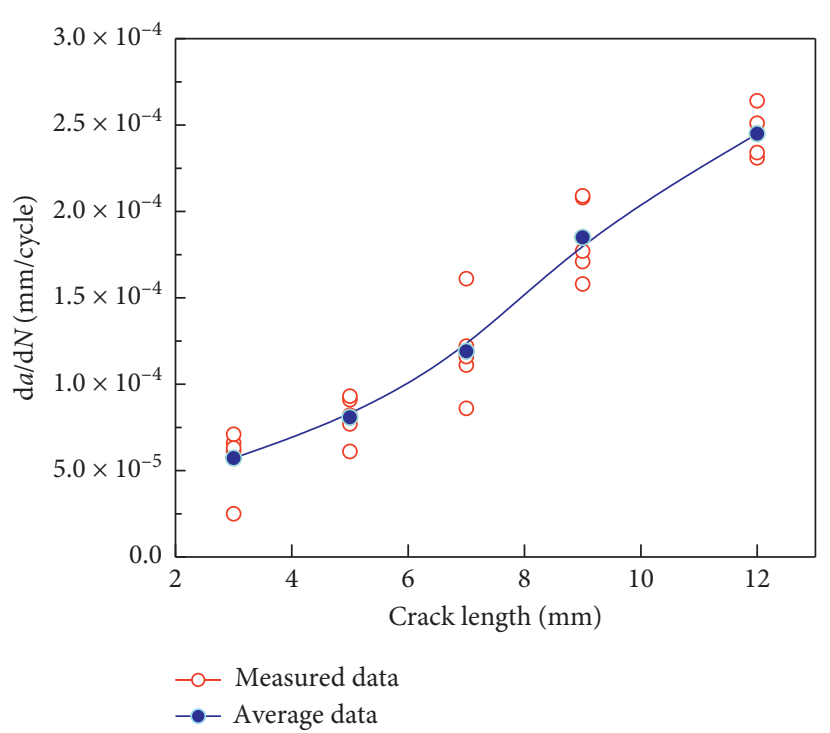

FIGURE 6: Crack growth rate at a given crack length in the precorrosion fatigue test when corrosion hours are $128 \mathrm{~h}$.

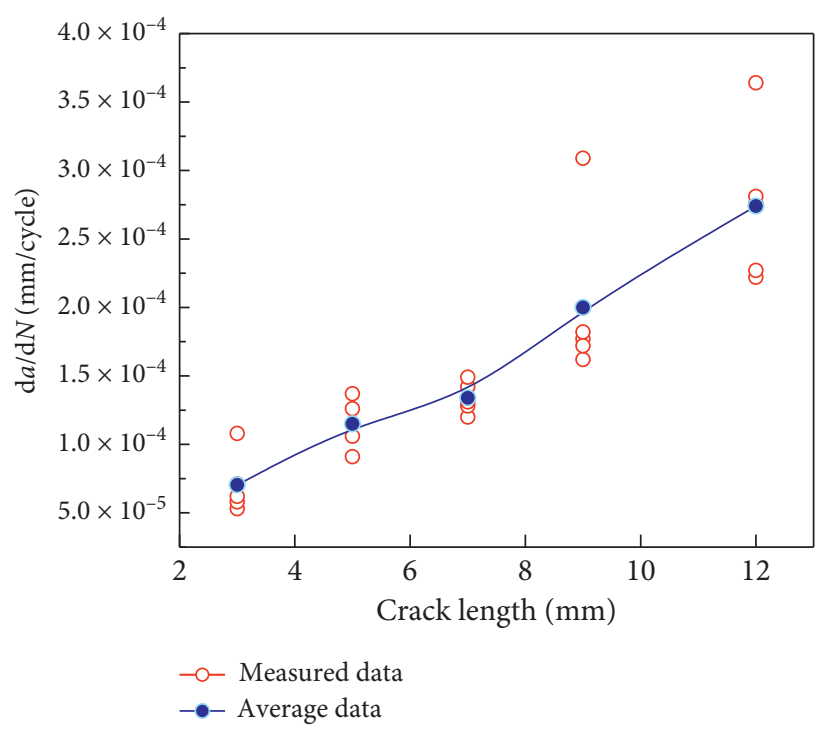

Figure 7: Crack growth rate at a given crack length in the precorrosion fatigue test when corrosion hours are $192 \mathrm{~h}$.

In the process of fatigue crack growth, the fatigue crack growth rate will suddenly change under the alternating action of corrosion and fatigue, and the fatigue crack growth rate will suddenly decrease. This is different from the precorrosion fatigue test. This is because, in the test of alternate corrosion and fatigue process, the plastic region and slip bands at the crack tip will be corroded preferentially with each action of corrosion. When the specimen is subjected to fatigue action again, the slip band needs to be reformed at the crack tip, and the fatigue crack can be extended forward through the accumulation of slip bands. It is found that the energy required to form a new slip band during fatigue crack growth process is greater than the energy required to extend forward on the basis of the original slip band. The schematic 


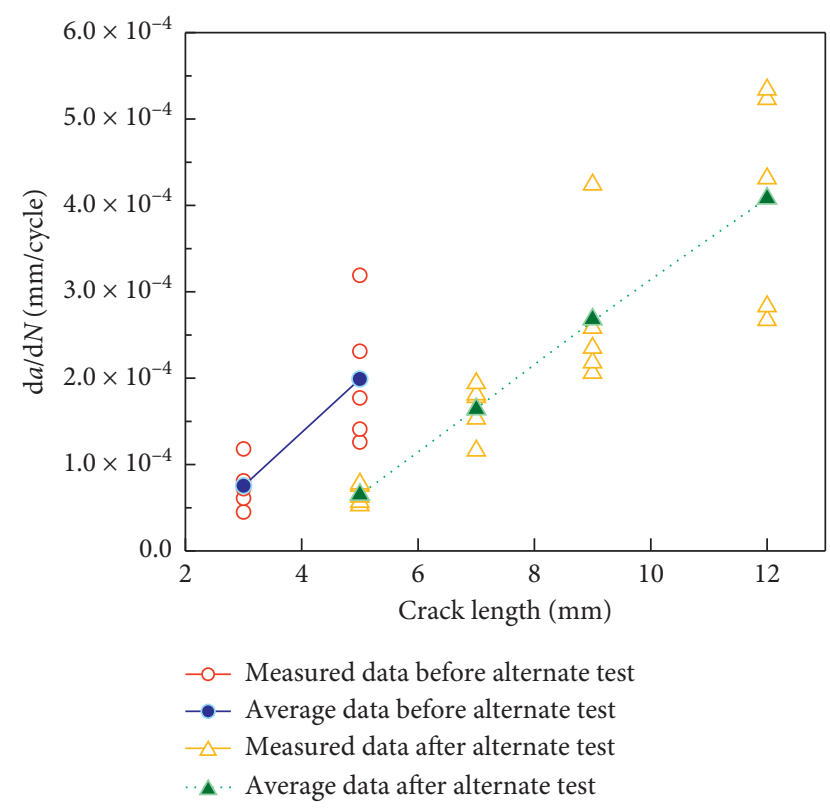

FIGURE 8: Crack growth rate at a given crack length in when alternate time is 2 and corrosion hours are $192 \mathrm{~h}$.

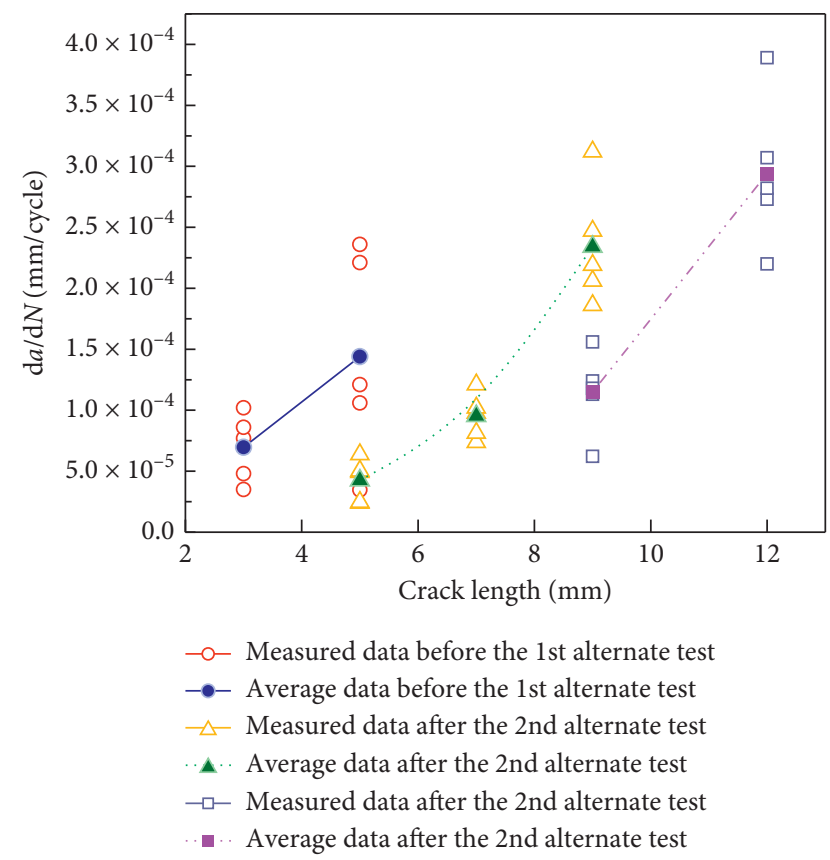

FIGURE 9: Crack growth rate at a given crack length when alternate time is 3 and corrosion hours are $192 \mathrm{~h}$.

diagram of the stress field at the crack tip can be seen from Figure 14.

Therefore, in the alternating process, the fatigue crack growth rate at the crack tip will decrease suddenly after corrosion action. With the growth of fatigue crack length, the influence of alternating action of corrosion on slip bands and fatigue crack growth is gradually weakened. In addition, the more times the corrosion fatigue alternates, the lower the fatigue crack growth rate will be at the position where the

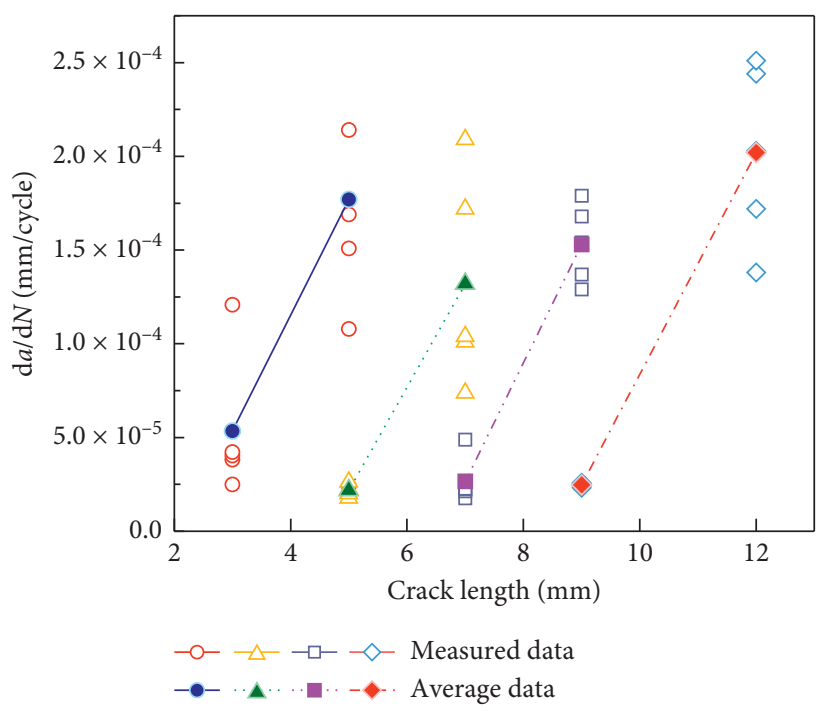

FIGURE 10: Crack growth rate at a given crack length when alternate time is 4 and corrosion hours are $192 \mathrm{~h}$.

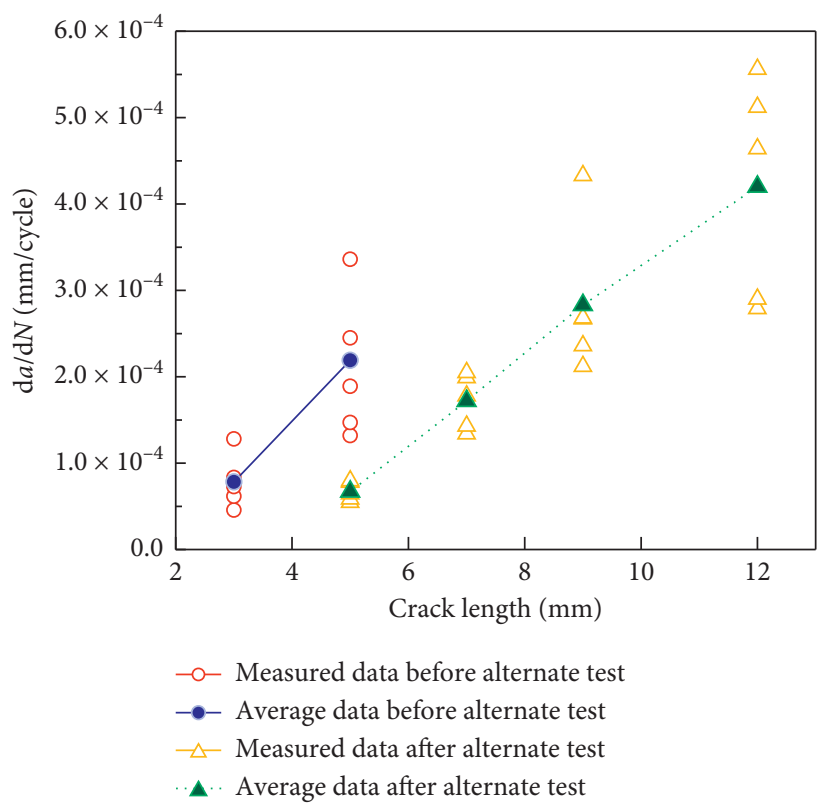

FIGURE 11: Crack growth rate at a given crack length when alternate time is 2 and corrosion hours are $128 \mathrm{~h}$.

fatigue cracks propagated again in the case of the same corrosion time. That is, the more the alternating times of corrosion and fatigue, the more obvious the retardation effect of corrosion on fatigue crack growth.

The pre-corrosion fatigue test is compared with the alternating corrosion fatigue test when the total corrosion time is the same. The average fatigue crack growth rate at different crack lengths was compared, as shown in Figures 15 and 16 .

As can be seen from Figures 15 and 16, the fatigue crack growth rate increased rapidly after alternating action of 


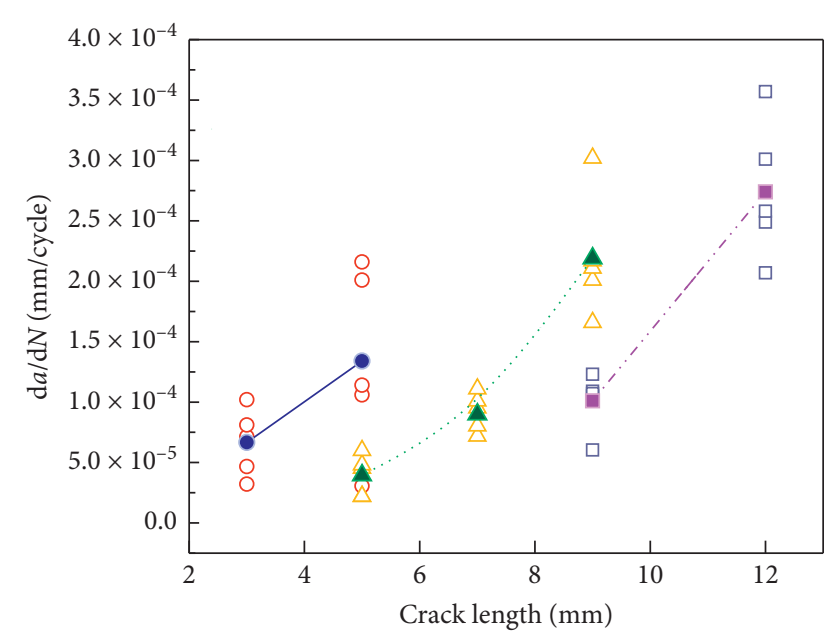

- - Measured data before the 1 st alternate test

$-\bullet$ Average data before the 1 st alternate test

$\triangle-$ Measured data after the 2 nd alternate test

-.. Average data after the 2 nd alternate test

$\rightarrow \square$ Measured data after the 2nd alternate test

.1. . Average data after the 2 nd alternate test

FIGURE 12: Crack growth rate at a given crack length when alternate time is 3 and corrosion hours are $128 \mathrm{~h}$.

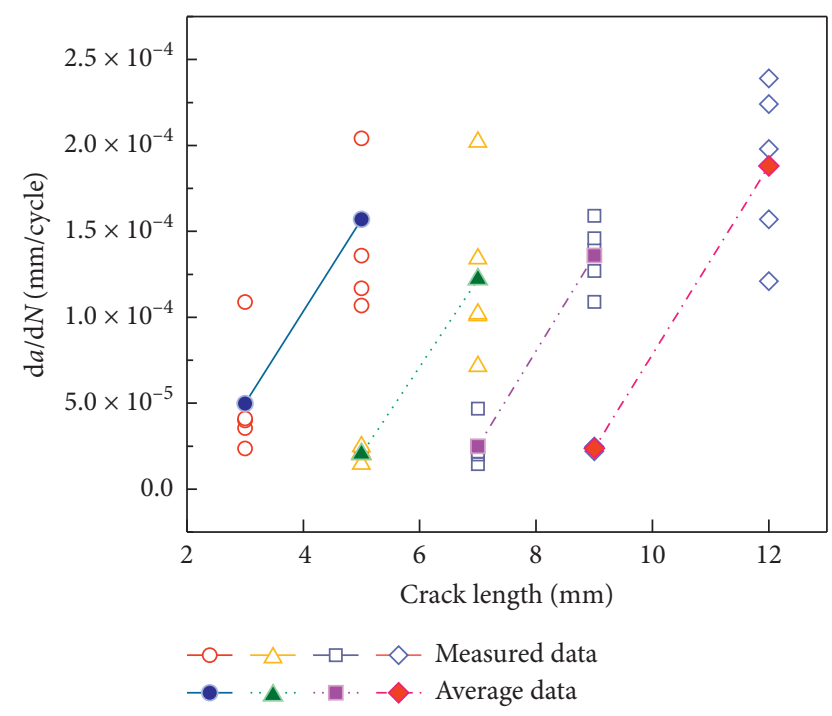

FIGURE 13: Crack growth rate at a given crack length when alternate time is 4 and corrosion hours are $128 \mathrm{~h}$.

corrosion and fatigue experiment. When the alternating times were 2, the fatigue crack growth rate was suddenly changed at $5 \mathrm{~mm}$, which was due to the hysteresis effect of corrosion on the fatigue crack growth. The fatigue crack growth rate reached the maximum when the crack length was $12 \mathrm{~mm}$, which was far greater than in other cases. When the alternating times were 3 , the fatigue crack growth rate was suddenly changed at $5 \mathrm{~mm}$ and $9 \mathrm{~mm}$, and the fatigue crack growth rate at $9 \mathrm{~mm}$ was significantly higher than that

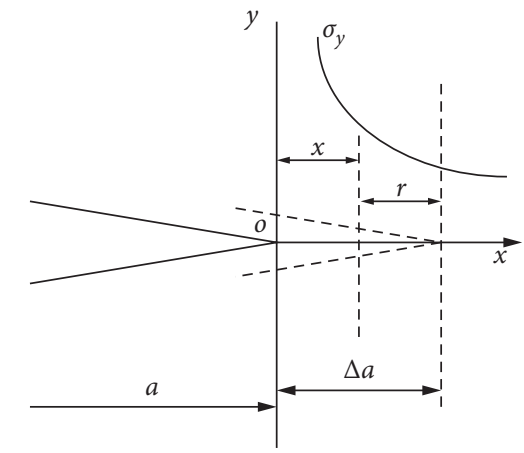

FIgURE 14: The schematic diagram of the stress field at the crack tip.

at $5 \mathrm{~mm}$. When the alternating times were 4 , the fatigue crack growth rate suddenly changed at $5 \mathrm{~mm}, 9 \mathrm{~mm}$, and $12 \mathrm{~mm}$, and the fatigue crack growth rate increased steadily with the increase of fatigue crack length.

\section{Fatigue Crack Growth Model under Alternate Corrosion and Fatigue}

4.1. Fatigue Crack Growth Model. The characteristics of fatigue crack growth under the alternating test of corrosion and fatigue are different from those of pure fatigue test and pre-corrosion fatigue test. The main reason is that the fatigue crack growth rate will change suddenly under the alternating action of corrosion and fatigue, which will have a certain hysteresis effect on the fatigue crack growth. In the alternating process, corrosion will first have a corrosive effect on the crack tip. Under the action of corrosion, corrosion pits will be formed in the plastic region and slip bands of the crack tip, as shown in Figure 17. Because of the existence of corrosion pits at the crack tip, the crack tip loses its blocking effect on the fatigue crack growth. This is equivalent to extending the tip of the crack forward by $\delta a$, where $\delta a$ is the depth of the corrosion pit along the crack.

It has been proved that the depth of the corrosion pit for aluminum alloy is proportional to the cube root of the time of corrosion. $b$ is the parameter related to material and environment, and $t$ is the time of corrosion.

$$
d=\delta a=b t^{1 / 3} .
$$

There are three commonly used corrosion pit models: nonlinear model, linear model, and phenomenon model.

$$
\left\{\begin{array}{l}
d=a t^{b} \text { (nonlinear model) } \\
d=A+b t^{c} \text { (linear model) } \\
d=a t^{b}-c \text { (phenomenon model). }
\end{array}\right.
$$

There are many models to describe the fatigue crack growth rate, such as the Forman equation, Wheeler model, and Willenborg model. Paris formula is the most commonly used fatigue crack growth rate model. $\Delta K$ is the amplitude of stress intensity factor, and $C$ and $n$ are material constants, respectively. 


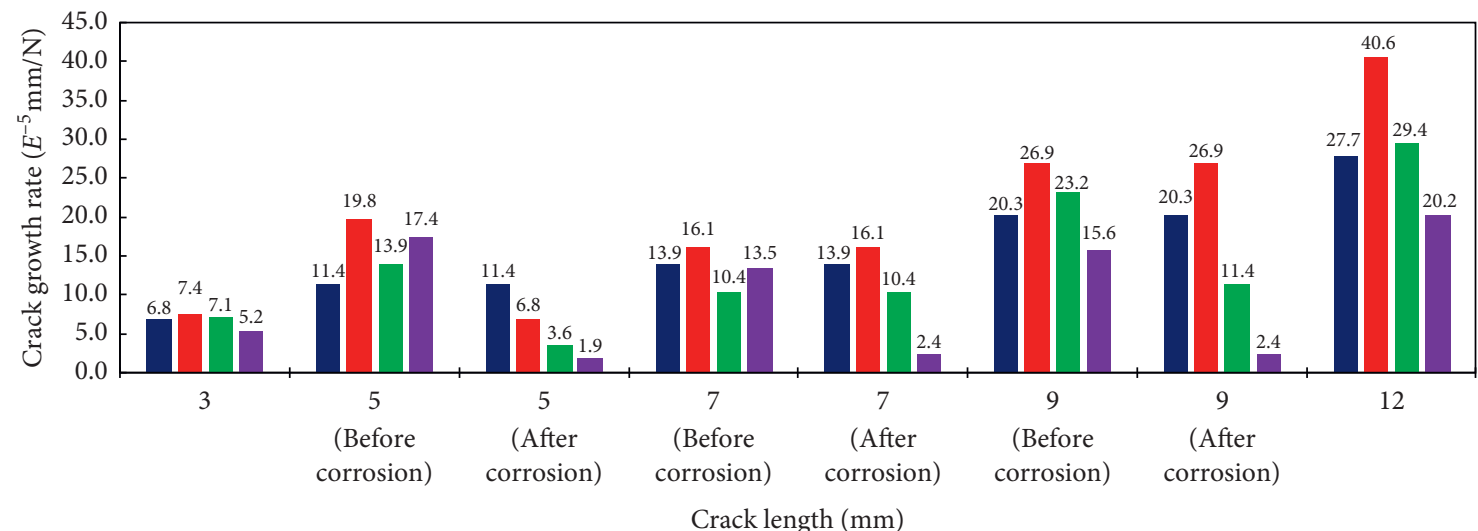

Pre-corrosion fatigue test

Twice alternating of corrosion and fatigue test
3 times alternating of corrosion and fatigue test

4 times alternating of corrosion and fatigue test

Figure 15: The average fatigue crack growth rate at different crack lengths (the total corrosion time is 192 hours).

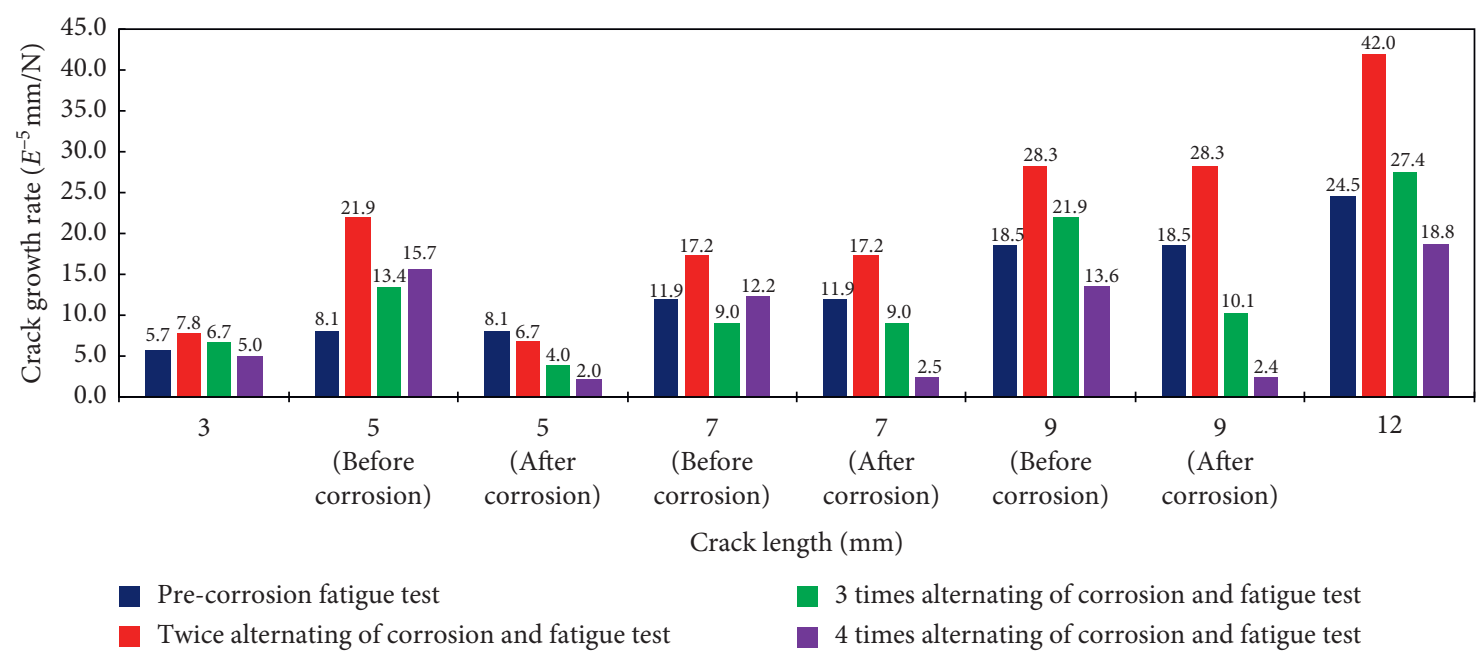

FIgURE 16: The average fatigue crack growth rate at different crack lengths (the total corrosion time is 128 hours).

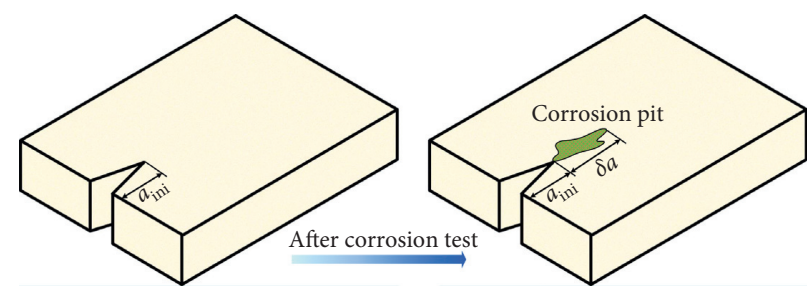

Figure 17: The schematic diagram of the dissolution process of the crack tip under the action of corrosion.

$$
\left(\frac{\mathrm{d} a}{\mathrm{~d} N}\right)=C(\Delta K)^{n} .
$$

For the stress field near the crack tip, the stress intensity factor can be calculated by formula (4). $\sigma$ is the stress, $F$ is the geometric correction factor, and $a$ is the actual length of the crack.

$$
K=\sigma F \sqrt{\pi a}
$$

The formula for calculating the amplitude of stress intensity factor can be expressed as the following formula. $\Delta \sigma$ is the magnitude of the stress amplitude.

$$
\Delta K=\Delta \sigma F \sqrt{\pi a} .
$$

For specimens with unilateral notch cracks, the geometric correction factor $F$ can be calculated according to the following equation. $W$ is the width of the specimen. 


$$
F=0.265\left(1-\frac{a}{W}\right)^{4}+\frac{0.857+0.265(a / W)}{(1-(a / W))^{1.5}}
$$

In the process of alternate corrosion and fatigue, the geometric correction coefficient of the specimen where the crack length is a can be expressed by the following equation:

$$
F^{\prime}=0.265\left(1-\frac{a+\delta a}{W}\right)^{4}+\frac{0.857+0.265((a+\delta a) / W)}{(1-((a+\delta a) / W))^{1.5}}
$$

The magnitude of stress intensity factor after corrosion can be expressed by the following formula:

$$
\Delta K^{\prime}=\Delta \sigma F^{\prime} \sqrt{\pi(a+\delta a)} .
$$

Because the alternating action of corrosion fatigue has a hysteresis effect on crack growth, and the hysteresis effect is determined by the corrosion time $t$, the concept of hysteresis factor is introduced. The hysteresis factor $\lambda$ reflects the hysteresis effect of corrosion on crack growth in alternating tests and it is a function of corrosion time in alternating tests. Meanwhile, the material and environment parameters $C$ and $n$ in the crack growth formula are the parameters related to corrosion time. Therefore, the fatigue crack growth rate can be expressed by the following formula in the alternate test of corrosion and fatigue:

$$
\left\{\begin{array}{l}
\left(\frac{\mathrm{d} a}{\mathrm{~d} N}\right)=C\left(\Delta K^{\prime}\right)^{n}, \\
C=\lambda_{c} f\left(t_{2}\right), \\
n=\lambda_{n} g\left(t_{2}\right), \\
\lambda_{c}=h\left(t_{1}\right), \\
\lambda_{n}=l\left(t_{1}\right) .
\end{array}\right.
$$

In formula (9), the corrosion time of $C$ and $n$ is composed of two parts. $t_{1}$ is the alternating corrosion time of the alternate test of corrosion and fatigue at a certain crack length, and $t_{2}$ is the corrosion time of the specimen after the alternate test of corrosion and fatigue at a certain crack length. $f\left(t_{2}\right)$ reflects the effect of precorrosion on the substrate of the specimen, and $f\left(t_{1}\right)$ reflects the effect of corrosion on the performance of the specimen in the alternating process. After the logarithmic operation of formula (9), the following formula can be further obtained:

$$
\log \left(\frac{\mathrm{d} a}{\mathrm{~d} N}\right)=\log C+n \log \left(\Delta K^{\prime}\right) .
$$

Therefore, the equations of fatigue crack growth rate can be expressed by the following formula when the alternate test of corrosion and fatigue is applied to multiple crack lengths in the process of fatigue crack growth:

$$
\left\{\begin{array}{c}
\frac{\mathrm{d} a_{1}}{\mathrm{~d} N}=C_{1}\left(\Delta K_{1}^{\prime}\right)^{n_{1}}\left(a_{1} \leq a \leq a_{2}\right), \\
\frac{\mathrm{d} a_{2}}{\mathrm{~d} N}=C_{2}\left(\Delta K_{2}^{\prime}\right)^{n_{2}}\left(a_{2} \leq a \leq a_{3}\right), \\
\vdots \\
\frac{\mathrm{d} a_{i}}{\mathrm{~d} N}=C_{i}\left(\Delta K_{i}^{\prime}\right)^{n_{i}}\left(a_{i-1} \leq a \leq a_{i}\right) .
\end{array}\right.
$$

4.2. Determination of Model Parameters and Verification of Accuracy. To determine the fatigue crack growth model of different alternate specimens of corrosion and fatigue, it is first necessary to determine the degree of corrosion at the tip of different specimens under different alternating corrosion times. That is to determine the corrosion pit depth of crack tip under different corrosion periods of time. In order to determine the relationship between corrosion pit depth and corrosion time, it is necessary to carry out the fatigue crack growth test under specific fatigue crack length and different corrosion periods of time. The depth of the corrosion pit was determined by microscopic measurement after the test. When the crack is equal to $5 \mathrm{~mm}$, the corrosion tests will be conducted for different corrosion periods of time. The groups of specimens are shown in Table 4 . The fatigue test was carried out on the groups of the specimens until fracture after the completion of the corrosion test.

The number of specimens in each group is 5 . The slices of fatigue fracture of the specimens after alternate action between corrosion and fatigue test were ground with a 1200 grit $\mathrm{SiC}$ paper and cleaned by ultrasonic wave using carbon tetrachloride. As can be seen from Figure 3(a), the corrosion region of the slip band is the measurement region of the corrosion depth of the fatigue crack tip after the corrosion test when the crack length is $5 \mathrm{~mm}$. The corrosion depth at the crack tip of different groups of specimens was measured by using an electron microscope. The measurement results are shown in Table 5.

According to the measured data and the length of the corrosion time, the least-square method was used to fit formula (1), and the relationship between the corrosion depth at the fatigue crack tip and the corrosion time was obtained as shown in Figure 18.

$$
d=0.00981 t^{0.39159} \text {. }
$$

The correlation coefficient $R=0.94977$ is well correlated with the experimental results. With the increase of corrosion time, the depth of corrosion gradually increases.

The pre-corrosion test without the alternate test of corrosion and fatigue was conducted on the specimens of 
TABLE 4: The measurement test of corrosion depth at the crack tip.

\begin{tabular}{lcc}
\hline Measurement test & $\begin{array}{c}\text { The crack length before } \\
\text { corrosion test }(\mathrm{mm})\end{array}$ & Corrosion time \\
\hline $4-1$ & 5 & $96 \mathrm{~h}$ \\
$4-2$ & 5 & $128 \mathrm{~h}$ \\
$4-3$ & 5 & $192 \mathrm{~h}$ \\
\hline
\end{tabular}

TABLE 5: Measurement results of corrosion depth at the fatigue crack tip.

\begin{tabular}{llllll}
\hline \multirow{2}{*}{ The groups of specimens } & \multicolumn{5}{c}{$\begin{array}{c}\text { The corrosion depth at fatigue } \\
\text { crack tip (mm) }\end{array}$} \\
\hline $4-1$ & 0.049 & 0.063 & 0.052 & 0.058 & 0.064 \\
$4-2$ & 0.066 & 0.074 & 0.069 & 0.061 & 0.072 \\
$4-3$ & 0.081 & 0.078 & 0.071 & 0.074 & 0.077 \\
\hline
\end{tabular}

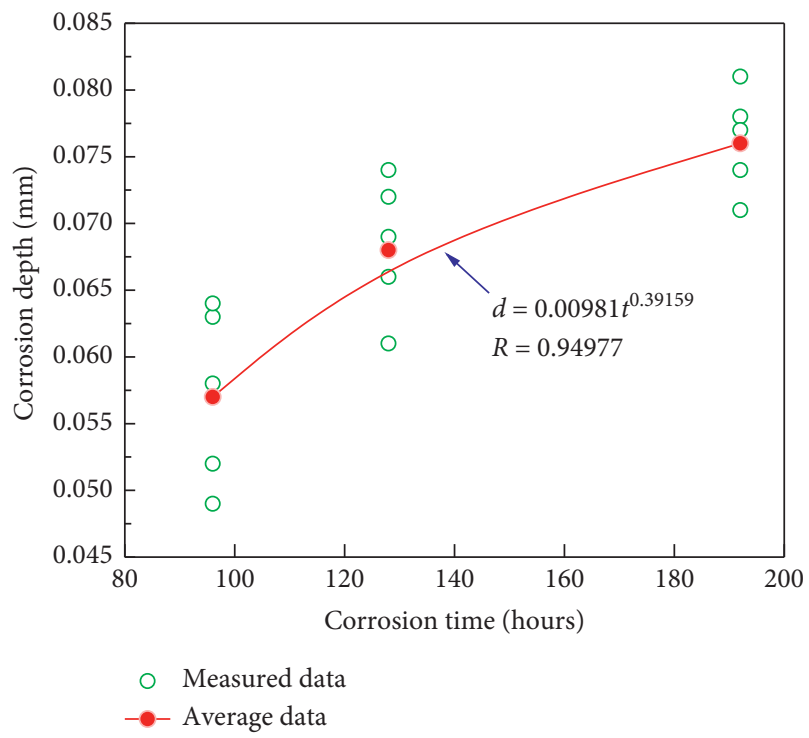

FIgURE 18: The test results and fitting curve between corrosion depth and corrosion time.

group 2-1 and group 2-2 only. Therefore, $f\left(t_{2}\right)$ of the specimens of group 2-1 and group 2-2 was 0 .

The crack growth rates in group 1-1, group 2-1, and group 2-2 at different crack lengths are shown in Figures 19 and 20. The least-square method was used to fit the fatigue crack growth equations of group 1-1, group 2-1, and group $2-2$, as shown in Table 6. The $C$ and $n$ values of each experimental group are shown in Table 7 .

By using the least-square method to fit the equation of $C$ and $n$ related to the corrosion time, the change rule of $C$ and $n$ with the corrosion time $t_{2}$ can be expressed as the following equation. The correlation coefficient of $C$ is 0.9807 and the correlation coefficient of $n$ is 0.9838 .

$$
\begin{aligned}
& C=f\left(t_{2}\right)=6 E^{-9} t_{2}^{2}+1 E^{-7} t_{2}+2 E^{-9} \\
& n=g\left(t_{2}\right)=-0.02 t_{2}+1.925
\end{aligned}
$$

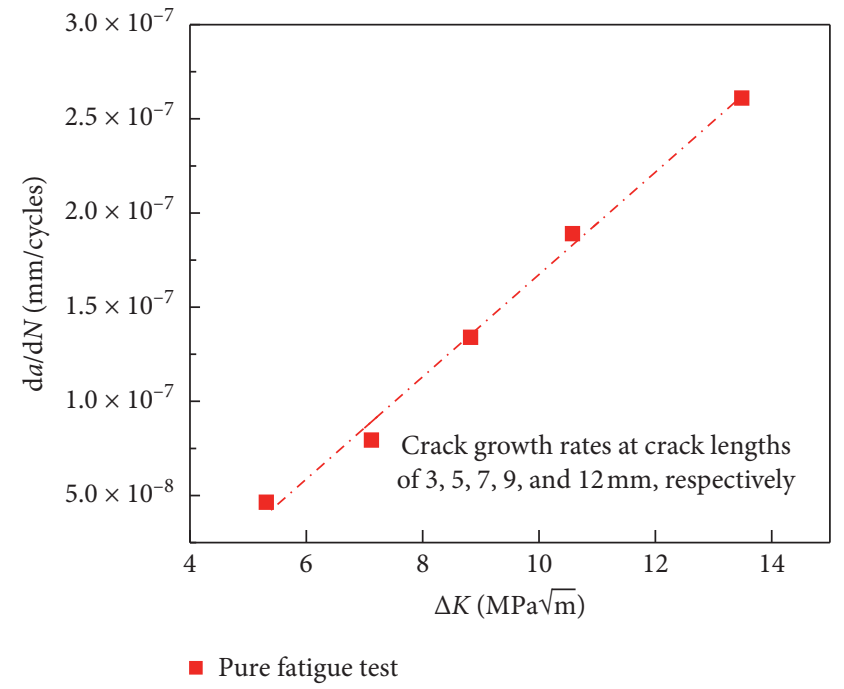

FIgURE 19: The crack growth rate in group 1-1 at different crack lengths.

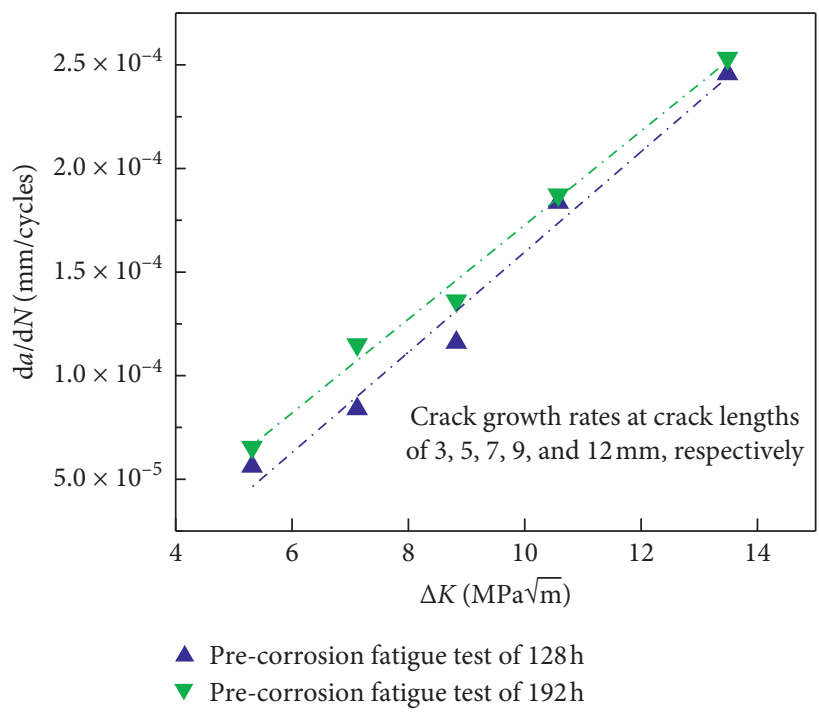

FIGURE 20: The crack growth rate in group 2-1 and group 2-2 at different crack lengths.

According to the experimental results of group 3-1, group 3-2 and, group 3-3 in the alternate test of corrosion and fatigue when the fatigue crack length is $5 \mathrm{~mm}$, the fatigue crack growth rate at the specific crack length was calculated as shown in Figure 21.

The experimental results were substituted into formula (10) to calculate material and environmental parameters $C$ and $n$ with different fatigue crack lengths by using the least square method and linear interpolation. Then, the fatigue crack growth equations of group 3-1, group 3-2, and group 3-3 are shown in Table 8. And Table 9 shows the values of $C$ and $n$ of each experimental group.

According to formulas (13) and (14), the values of $C$ and $n$ corresponding to the corrosion time of group 3-1, group 
TABLE 6: The fatigue crack growth rate equations of group 1-1, group 2-1, and group 2-2.

\begin{tabular}{lccc}
\hline Group & Corrosion time & Crack growth rate equations & Correlation coefficient \\
\hline $1-1$ & 0 & $\log (\mathrm{d} a / \mathrm{d} N)=1.9131 \log (\Delta K)-8.7125$ & 0.9909 \\
$2-1$ & $128 \mathrm{~h}$ & $\log (\mathrm{d} a / \mathrm{d} N)=1.6405 \log (\Delta K)-5.4563$ & 0.988 \\
$2-2$ & $192 \mathrm{~h}$ & $\log (\mathrm{d} a / \mathrm{d} N)=1.4211 \log (\Delta K)-5.1921$ & 0.9863 \\
\hline
\end{tabular}

TAвLe 7: The values of $C$ and $n$ in group 1-1, group 2-1 and group 2-2.

\begin{tabular}{lccc}
\hline Group & Corrosion time & $C$ & $n$ \\
\hline $1-1$ & 0 & $1.93865 E-09$ & 1.9131 \\
$2-1$ & $128 \mathrm{~h}$ & $3.49704 E-06$ & 1.6405 \\
$2-2$ & $192 \mathrm{~h}$ & $6.4254 E-06$ & 1.4211 \\
\hline
\end{tabular}

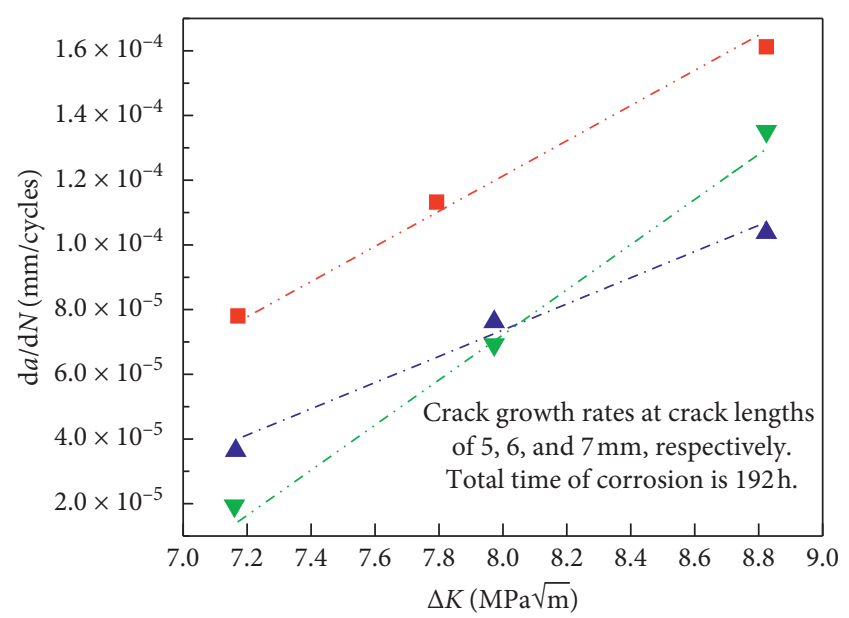

- Alternate 2 times of corrosion fatigue

- Alternate 3 times of corrosion fatigue

$\nabla$ Alternate 4 times of corrosion fatigue

FIGURE 21: The crack growth rate in group 3-1, group 3-2, and group 3-3 at different crack lengths.

3-2, and group 3-3 before the alternate test of corrosion and fatigue can be obtained when the fatigue crack length is $5 \mathrm{~mm}$. Therefore, the values of $C$ and $n$ under the action of alternate corrosion and fatigue can be further calculated, as shown in Table 10.

According to the least square method, the hysteresis factor and the corrosion time of alternating action are fitted, and the fitting results can be expressed by the following formula as shown in (15). The group of formulas of (16) represents the equation of fatigue crack growth rate under the alternating action of corrosion and fatigue. In the group of formulas of (16), $\left(\mathrm{d} a_{i} / \mathrm{d} N\right)=C_{i}\left(\Delta K^{\prime}\right)^{n}, C_{i}=\lambda_{c i}\left(6 E^{-9} t_{2}^{2}\right.$ $\left.+1 E^{-7} t_{2}+2 E^{-9}\right), n_{i}=\lambda_{n i}\left(-0.02 t_{2 i}+1.925\right), \lambda_{c i}=1.3739 E^{-9}$ $\left(1+t_{1 i}\right)^{5.8734}$, and $\lambda_{n i}=11.2777 *(0.87674)^{t_{1 i}}$. It can be seen that, in the process of alternating corrosion and fatigue, the fatigue crack growth rate is not only determined by the length of fatigue crack but also affected by the corrosion time and the alternate time of corrosion and fatigue. The effect rule is shown in Figures 20 and 21. As the total corrosion time increases, the material constants $C$ and $n$ increase rapidly.

$$
\begin{aligned}
& \left\{\begin{array}{l}
\lambda_{c}=1.3739 E^{-9}\left(1+t_{1}\right)^{5.8734} \\
R^{2}=0.9973 \\
\lambda_{n}=11.2777 *(0.87674)^{t_{1}} \\
R^{2}=0.9869
\end{array}\right. \\
& \left\{\begin{array}{l}
\frac{\mathrm{d} a_{1}}{\mathrm{~d} N}=C_{1}\left(\Delta K_{1}^{\prime}\right)^{n_{1}}\left(a_{1} \leq a \leq a_{2}\right) \\
\frac{\mathrm{d} a_{2}}{\mathrm{~d} N}=C_{2}\left(\Delta K_{2}^{\prime}\right)^{n_{2}}\left(a_{2} \leq a \leq a_{3}\right) \\
\vdots \\
\frac{\mathrm{d} a_{i}}{\mathrm{~d} N}=C_{i}\left(\Delta K_{i}^{\prime}\right)^{n_{i}}\left(a_{i-1} \leq a \leq a_{i}\right)
\end{array}\right.
\end{aligned}
$$

When the fatigue crack length was $5 \mathrm{~mm}$, the specimens of group 3-4 were subjected to the alternate test of corrosion and fatigue, and the total test time after the alternate test of corrosion and fatigue was 64 hours. According to the experimental record results and Tables $6-8$, the fatigue crack growth rate of the specimens in group 3-4 was calculated by using the established prediction model when the fatigue crack length was $7 \mathrm{~mm}, 9 \mathrm{~mm}$, and $12 \mathrm{~mm}$ after the alternate action of corrosion and fatigue when the fatigue crack length was $5 \mathrm{~mm}$. And the calculated result was compared with the experimental results as shown in Table 11. And the effects of alternate time of corrosion and fatigue and total corrosion time on material constant of $C$ and $n$ are shown in Figures 22 and 23.

As can be seen from Table 11, the prediction error between the experimental results and the predicted results from the model of the fatigue crack growth rate is little. When the fatigue crack length is $9 \mathrm{~mm}$, the predicted result is larger than the actual fatigue crack growth rate. When the crack grows to $10 \mathrm{~mm}$, the prediction results are smaller than the experimental results, but the prediction error all satisfied the actual engineering application requirements. In particular, the prediction of fatigue crack growth rate after alternate 
TABLE 8: The equations of fatigue crack growth rate of group 3-1, group 3-2, and group 3-3.

\begin{tabular}{llc}
\hline Specimen & Equations of fatigue crack growth rate & Correlation coefficient \\
\hline $3-1$ & $\log (\mathrm{d} a / \mathrm{d} N)=4.0053 \log (\Delta K)-7.5519$ & 0.896 \\
$3-2$ & $\log (\mathrm{d} a / \mathrm{d} N)=5.0504 \log (\Delta K)-8.7242$ & 0.9353 \\
$3-3$ & $\log (\mathrm{d} a / \mathrm{d} N)=9.3121 \log (\Delta K)-12.658$ & 0.9951 \\
\hline
\end{tabular}

TABLE 9: The values of $C$ and $n$ of group 3-1, group 3-2, and group 3-3 before the alternate test of corrosion and fatigue.

\begin{tabular}{lccr}
\hline Specimen & Corrosion time of each alternate cycle $(\mathrm{h})$ & $C$ & $n$ \\
\hline $3-1$ & 96 & $2.80608 E-08$ & 4.0053 \\
$3-2$ & 64 & $1.88712 E-09$ & 5.0504 \\
$3-3$ & 48 & $2.19786 E-13$ & 9.3121 \\
\hline
\end{tabular}

TAвLE 10: The values of $C$ and $n$ of group 3-1, group 3-2, and group 3-3 after the alternate test of corrosion and fatigue.

\begin{tabular}{|c|c|c|c|c|}
\hline Specimen & $C$ (after alternate test) (E) & $n$ (after alternate test) & $\lambda_{c}$ & $\lambda_{n}$ \\
\hline $3-1$ & $5.858-6$ & 1.445 & $4.79 E-03$ & 2.771834 \\
\hline $3-2$ & $3.138-6$ & 1.605 & $6.01 E-04$ & 3.146667 \\
\hline $3-3$ & $2.066-6$ & 1.685 & $1.06 E-07$ & 5.526469 \\
\hline
\end{tabular}

TABLE 11: The comparison of the fatigue crack growth rate between prediction results and experimental results.

\begin{tabular}{lccc}
\hline $\begin{array}{l}\text { Crack } \\
\text { length } \\
(\mathrm{mm})\end{array}$ & $\begin{array}{c}\text { Experimental } \\
\text { result }\end{array}$ & $\begin{array}{c}\text { Prediction } \\
\text { result }\end{array}$ & $\begin{array}{c}\text { Prediction } \\
\text { error }(\%)\end{array}$ \\
\hline 9 & $5.19 E^{-5}(\mathrm{~mm} / \mathrm{N})$ & $5.30 E^{-5}(\mathrm{~mm} / \mathrm{N})$ & 2.07 \\
10 & $11.19 E^{-5}(\mathrm{~mm} / \mathrm{N})$ & $8.74 E^{-5}(\mathrm{~mm} / \mathrm{N})$ & -21.9 \\
11 & $17.52 E^{-5}(\mathrm{~mm} / \mathrm{N})$ & $14.56 E^{-5}(\mathrm{~mm} / \mathrm{N})$ & -16.9 \\
12 & $28.34 E^{-5}(\mathrm{~mm} / \mathrm{N})$ & $23.95 E^{-5}(\mathrm{~mm} / \mathrm{N})$ & -15.5 \\
\hline
\end{tabular}

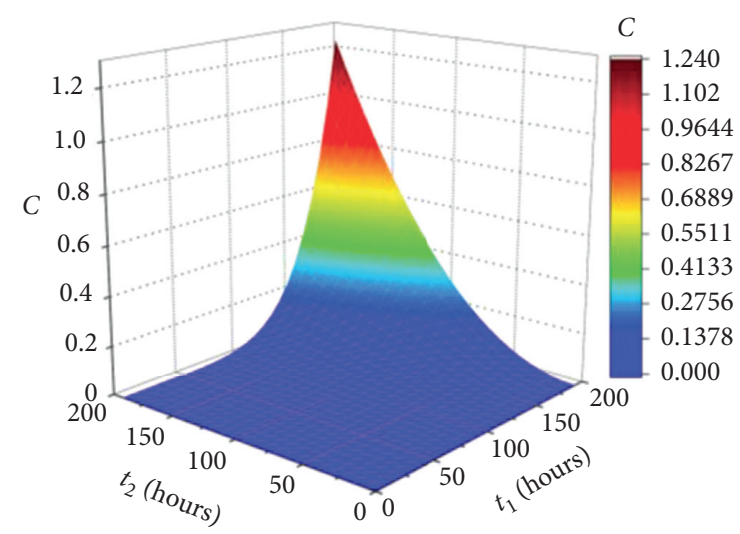

FIgURE 22: The effect of alternate time of corrosion and fatigue and total corrosion time on the material constant of $C$.

action of corrosion and fatigue is highly accurate. Because the environmental spectrum used in the process of alternate process of corrosion and fatigue is the accelerated environmental spectrum that simulated the actual atmospheric environment, the established model of fatigue crack growth rate under the alternate action of corrosion and fatigue has certain engineering application value.

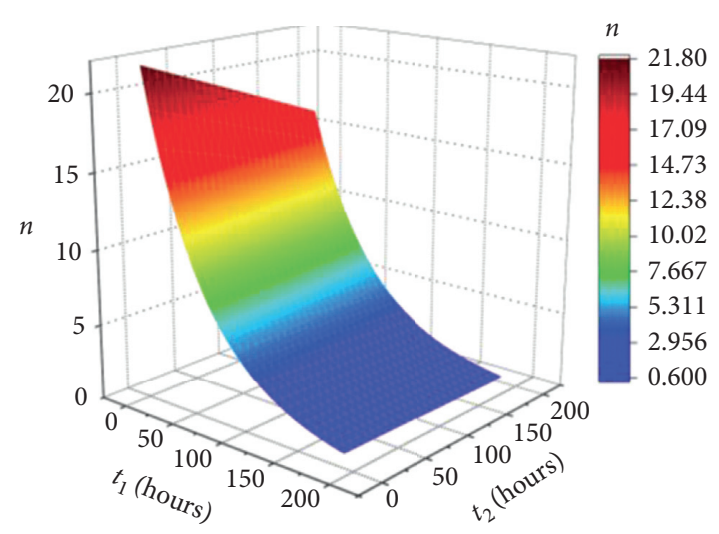

FIgURE 23: The effect of alternate time of corrosion and fatigue and total corrosion time on the material constant of $n$.

\section{Conclusions}

The fatigue crack growth characterizations of the 2024-T4 aluminum alloy under the alternate action of corrosion and fatigue were studied by experiments, and the following conclusions were obtained.

(1) The fatigue crack growth experiments of pure fatigue, pre-corrosion fatigue, and alternate corrosion 
and fatigue of 2024-t4 aluminum alloy were carried out. And the corrosion test carried out by using the corrosion accelerated environmental spectrum simulated the actual atmospheric environment. The effect of pure fatigue, pre-corrosion fatigue, and alternate corrosion fatigue on the fatigue crack growth life of specimens was analyzed. It is found that the fatigue crack growth life of the specimens corroded was smaller than that of the specimens under pure fatigue action. However, the fatigue crack life of alternate corrosion and fatigue is longer than that of pre-corrosion fatigue when the corrosion time is the same. Moreover, the more times of alternating under the same corrosion time, the longer the fatigue crack growth life will be.

(2) The fatigue crack growth rate under corrosion is much higher than that under pure fatigue. However, under the alternating action of corrosion and fatigue, the fatigue crack growth rate of the specimens presents the characteristic of discontinuous change. After alternate action of corrosion and fatigue, the fatigue crack growth rate will decrease suddenly. The dissolution of the plastic region at the fatigue crack tip is the main reason for the sudden change of fatigue crack growth rate.

(3) The hysteresis effect of corrosion on fatigue crack growth under the alternating action of corrosion and fatigue is analyzed and the concept of hysteresis factor $\lambda$ is introduced. By modifying the Paris formula, the prediction model of fatigue crack rate under alternating action of corrosion and fatigue was established. The parameters $C$ and $n$ of the fatigue crack growth formula are determined by the experimental results. The accuracy of the established crack rate prediction model is proved by comparing its results with the experimental results. The results show that the prediction model has a certain value in engineering application.

\section{Data Availability}

All data included in this study are available upon request by contact with the corresponding author.

\section{Conflicts of Interest}

The authors declare that they have no conflicts of interest.

\section{Acknowledgments}

The authors gratefully acknowledge the financial support of the National Defense Pre-Research Foundation of China (61409220202), the Natural Science Foundation of Shaanxi Province (2018JQ5012), and the China Postdoctoral Science Foundation (2017M623418).

\section{References}

[1] S. Sun, Q. Zheng, D. Li, and J. Wen, "Long-term atmospheric corrosion behaviour of aluminium alloys 2024 and 7075 in urban, coastal and industrial environments," Corrosion Science, vol. 51, no. 4, pp. 719-727, 2009.

[2] S. Sun, Q. Zheng, D. Li, S. Hu, and J. Wen, "Exfoliation corrosion of extruded 2024-T4 in the coastal environments in China," Corrosion Science, vol. 53, no. 8, pp. 2527-2538, 2011.

[3] N. Zhao, Y.-q. Yang, M. Han, X. Luo, G.-h. Feng, and R.-j. Zhang, "Finite element analysis of pressure on 2024 aluminum alloy created during restricting expansion-deformation heat-treatment," Transactions of Nonferrous Metals Society of China, vol. 22, no. 9, pp. 2226-2232, 2012.

[4] Z. Huda, N. I. Taib, and T. Zaharinie, "Characterization of 2024-T3: an aerospace aluminum alloy," Materials Chemistry and Physics, vol. 113, no. 2-3, pp. 515-517, 2009.

[5] S. Zhang, T. Zhang, Y. He, X. Du, B. Ma, and T. Zhang, "Longterm atmospheric pre-corrosion fatigue properties of epoxy primer-coated 7075-T6 aluminum alloy structures," International Journal of Fatigue, vol. 129, p. 105225, 2019.

[6] S. Zhang, T. Zhang, Y. He et al., "Effect of coastal atmospheric corrosion on fatigue properties of 2024-T4 aluminum alloy structures," Journal of Alloys and Compounds, vol. 802, pp. 511-521, 2019.

[7] R. Akid and K. J. Miller, "The effect of $\mathrm{pH}$ on the initiation and growth of short fatigue cracks," Advanced Engineering Materials, vol. 3, pp. 1403-1409, 1990.

[8] K. J. Miller and R. Akid, "The application of microstructural fracture mechanics to various metal surface states," Materials Science, vol. 33, no. 1, pp. 1-20, 1997.

[9] M. E. Hoffman and P. C. Hoffman, "Corrosion and fatigue research - structural issues and relevance to naval aviation," International Journal of Fatigue, vol. 23, pp. 1-10, 2001.

[10] J. Medved, M. Breton, and P. E. Irving, "Corrosion pit size distributions and fatigue lives-a study of the EIFS technique for fatigue design in the presence of corrosion," International Journal of Fatigue, vol. 26, no. 1, pp. 71-80, 2004.

[11] P. C. Hoffman, "Fleet management issues and technology needs," International Journal of Fatigue, vol. 31, no. 11-12, pp. 1631-1637, 2009.

[12] N. E. C. Co and J. T. Burns, "Effects of macro-scale corrosion damage feature on fatigue crack initiation and fatigue behavior," International Journal of Fatigue, vol. 103, pp. 234247, 2017.

[13] R. J. H. Wanhill and J. J. De Luccia, “An AGARD-coordinated corrosion fatigue cooperative testing programme," 1982.

[14] A. K. Vasudévan and S. Suresh, "Influence of corrosion deposits on near-threshold fatigue crack growth behavior in 2xxx and 7xxx series aluminum alloys," Metallurgical Transactions A, vol. 13, no. 12, pp. 2271-2280, 1982.

[15] B. Shafiq and V. S. Agarwala, "Corrosion fatigue in 7075-T6 aluminum: life prediction issues for carrier based operations," Journal of Aircraft, vol. 41, no. 2, pp. 393-398, 2004.

[16] D. L. Simpson and C. L. Brooks, "Tailoring the structural integrity process to meet the challenges of aging aircraft," International Journal of Fatigue, vol. 21, pp. S1-S14, 1999.

[17] A. S. Sergei, "Location of the fracture process for hydrogeninduced corrosion fatigue crack zone propagation," Scripta Materialia, vol. 47, no. 5, pp. 301-305, 2009.

[18] S. A. Shipilov, "Mechanisms for Fracture of Engineering Materials corrosion fatigue crack propagation," Fatigue, vol. 25, no. 3, pp. 243-259, 2002. 
[19] X. D. Li, X. S. Wang, H. H. Ren, Y. L. Chen, and Z. T. Mu, "Effect of prior corrosion state on the fatigue small cracking behavior of 6151-T6 aluminum alloy," Corrosion Science, vol. 55, pp. 26-33, 2012.

[20] F. Menan and G. Henaff, "Synergistic action of fatigue and corrosion during crack growth in the 2024 aluminum alloy," Proceedings of Engineering, vol. 2, no. 1, pp. 1441-1450, 2010.

[21] H. P. Seifert, S. Ritter, and H. J. Leber, "Corrosion fatigue initiation and short crack growth behavior of austenitic stainless steels under light water reactor conditions," Corrosion Science, vol. 59, pp. 61-75, 2012.

[22] R. M. Nejad, K. Farhangdoost, and M. Shariati, "Numerical study on fatigue crack growth in railway wheels under the influence of residual stresses," Engineering Failure Analysis, vol. 52, pp. 75-89, 2015.

[23] M. Shariati, E. Mohammadi, and R. M. Nejad, "Effect of a new specimen size on fatigue crack growth behavior in thickwalled pressure vessels," International Journal of Pressure Vessels and Piping, vol. 150, pp. 1-10, 2017.

[24] R. M. Nejad, K. Farhangdoost, M. Shariati, and M. Moavenian, "Stress intensity factors evaluation for rolling contact fatigue cracks in rails," Tribology Transactions, vol. 60, no. 4, pp. 645-652, 2017.

[25] Y. Huang, X. Ye, B. Hu, and L. Chen, "Equivalent crack size model for pre-corrosion fatigue life prediction of aluminum alloy 7075-T6," International Journal of Fatigue, vol. 88, pp. 217-226, 2016.

[26] S. Ishihara, S. Saka, Z. Y. Nan, T. Goshima, and S. Sunada, "Prediction of corrosion fatigue lives of aluminum alloy on the basis of corrosion pit growth law," Fatigue \& Fracture of Engineering Materials \& Structures, vol. 29, no. 6, pp. 472480, 2006.

[27] Y. Huang, S. T. Tu, and F. Z. Xuan, "Pit to crack transition behavior in proportional and non-proportional multiaxial corrosion fatigue of 304 stainless steel," Engineering Fracture Mechanics, vol. 184, pp. 259-272, 2017.

[28] F. Menan and G. Henaff, "Influence of frequency and exposure to a saline solution on the corrosion fatigue crack growth behavior of the aluminum 2024," International Journal of Fatigue, vol. 31, no. 11-12, pp. 1684-1695, 2009.

[29] C. Li, Y. He, Y. Feng, L. Wu, and S. Zhang, "The reliability life of 7B04 aluminum alloy under alternate action of corrosion and fatigue," Mathematical Problems in Engineering, vol. 3, pp. 1-9, 2016.

[30] F. Vucko, N. Lebozec, D. Thierry et al., "Combined corrosion and fatigue performance of joined materials for automotive applications," Materials and Corrosion, vol. 67, no. 11, pp. 1143-1151, 2016.

[31] M. L. Du, F. P. Chiang, S. V. Kagwade, and C. R. Clayton, "Damage of Al 2024 alloy due to sequential exposure to fatigue, corrosion and fatigue," International Journal of Fatigue, vol. 20, no. 10, pp. 743-748, 1998.

[32] B. Huneau and J. Mendez, "Evaluation of environmental effects on fatigue crack growth behavior of a high strength steel in a saline solution with cathodic protection," International Journal of Fatigue, vol. 28, no. 2, pp. 124-131, 2006.

[33] K. C. Hsu and C. K. Lin, "Effects of R-ratio on high-temperature fatigue crack growth behavior of a precipitationhardening stainless steel," International Journal of Fatigue, vol. 30, no. 12, pp. 2147-2155, 2008.

[34] Y.-K. Kim and D.-S. Shim, "The variation in fatigue crack growth due to the thickness effect," International Journal of Fatigue, vol. 22, pp. 611-618, 2000.
[35] D. Gary Harlow and R. P. Wei, "Probability modeling and material microstructure applied to corrosion and fatigue of aluminum and steel alloys," Engineering Fracture Mechanics, vol. 76, pp. 695-708, 2009.

[36] W. Q. Zhu, Y. K. Lin, and Y. Lei, "On fatigue crack growth under random loading," Engineering Fracture Mechanics, vol. 43, pp. 1-12, 1992.

[37] Y. K. Lin and J. N. Yang, "On statistical moments of fatigue crack propagation," Engineering Fracture Mechanics, vol. 18, pp. 243-262, 1983.

[38] Y. K. Lin and J. N. Yang, "A stochastic theory of fatigue crack propagation,” AIAA Journal, vol. 23, pp. 117-124, 1985.

[39] Y. K. Lin, W. F. Wu, and J. N. Yang, Probabilistic Methods in Mechanics of Solids and structure, Springer, Berlin, Germany, 1985.

[40] A. Tsurui and H. Ishikawa, "Application of Fokker-Planck equation to a stochastic fatigue crack growth model," Structural Safety, vol. 4, pp. 15-29, 1986.

[41] J. L. Bogdanoff and F. Kozin, Probabilistic Models of Cumulative Damage, Wiley, New York, NY, USA, 1985.

[42] W. F. Wu, C. S. Shin, and J. J. Shen, "Probabilistic analysis of fatigue crack propagation under random loading," The Journal of Pressure Vessel Technology, vol. 116, pp. 216-225, 1994.

[43] M. M. Rocha and G. I. Schueller, "A probabilistic criterion for evaluating the goodness of fatigue crack growth models," Engineering Fracture Mechanics, vol. 53, pp. 701-731, 1996.

[44] M. M. Rocha, G. I. Schueller, and H. Okamura, "The fitting of one- and two-dimensional fatigue crack growth laws," Engineering Fracture Mechanics, vol. 44, pp. 473-480, 1993.

[45] Y. Chen, C. Liu, J. Zhou, and F. Wang, "Effect of alternate corrosion factors on multiaxial low-cycle fatigue life of 2024T4 aluminum alloy," Journal of Alloys and Compounds, vol. 772, pp. 1-14, 2019. 